\title{
AN EXPERIMENTAL STUDY ON DEPENDENCE OF TIME INTERVALS FOR CONNECTIONS ON OPTIMIZATION COMPUTATIONS FOR TASK OF AIRCRAFT SCHEDULING
}

\begin{abstract}
Mathematical models are often employed for optimization of different problems arising in transport. It is a well-known fact that calculation times, which are necessary to find out an optimal solution, usually increase together with increasing scale of mathematical models (scale is defined by the number of variables and constraints that form each mathematical model). For some types of linear models (usually for the models in which logical or integer variables are used) it often happens that if scale of the model exceeds a certain limit, the model can be solved exactly either with big difficulties or cannot be solved at all. It is also known that the limit for which the model has the problem with its solvability depends on the type of the model. The paper is focused on an estimation of the solvability limit for the task of optimal aircraft scheduling for a charter airline.
\end{abstract}

Keywords: Aircraft scheduling, Linear programming, scale, solvability.

\section{Introduction - our motivation to solve the problem}

Aircraft scheduling is a basic problem which must be solved by airlines again and again [1]. A flight schedule which is well designed enables to plan effectively the most of operating activities that the airline must carry out. If the activities are not planned well, other redundant costs usually arise. In air transport, the redundant costs may essentially increase operating costs of the airline.

The paper is a continuation of thesis [2]. The thesis had two basic goals. The first goal of the thesis was to find out ways how charter airlines in the Czech Republic create the flight schedules. The author found out that the charter airlines do not employ any optimization methods for planning the operating activities. The second goal was to propose a mathematical model which was able to plan one of the operating activities - namely time positions of charter flights (flight scheduling) - effectively. The author stated that the optimal flight schedule is such schedule for which we need the minimal number of aircraft to serve all the planned flights. However, we usually meet with the minimization of the number of used transport means when we plan vehicle scheduling. Nevertheless, optimization methods enable us to join both problems and solve them simultaneously. The goal of the paper is to ascertain how the computation times depend on changes in input data values.

\section{The state of the art}

The optimization methods have been successfully employed for solving a lot of problems from practice. In the section we focus on some applications which are devoted to passenger transport in general. After it we present some concrete applications in air transport.

The optimization methods are most often used for planning route nets [3], [4], [5] and [6], for creating tariff zones [7], [8], [9] and [10], for time coordination of connections [11] and [12] or for vehicle scheduling [13], [14], [15] and [16].

In air transport, the optimization methods have been used for example for planning flight or crew timetables [17], maintenance [18] or for planning flight progress [19]. In literature, we can often meet with some combinations of different optimization tasks which have been listed in the previous text. Most often, flight scheduling is combined with crew scheduling [20] or flight scheduling with maintenance scheduling [21]. To solve the tasks connected with air transport linear programming [17], dynamic programming [18] or various heuristic methods [21] or memetic algorithms [22] are applied.

In the following section of the paper the solved task will be defined and its model will be presented. Further, some experiments with the model will be carried out in order to satisfy the goal of the paper.

\footnotetext{
* Vojtech Graf, Dusan Teichmann, Michal Dorda

Institute of Transport, Faculty of Mechanical Engineering, VSB - Technical University of Ostrava, Ostrava-Poruba, Czech Republic

E-mail: vojtech.graf@vsb.cz
} 


\section{Mathematical model}

Let a set $I$ of connections, which must be served, be given. For the defined set of the connections a time interval of a length $d k$, in which the departure must be realized, is specified. For each connection $i \in I$ a flight time $t_{i}$ and a time $\tau_{i}$ necessary for a consecutive flight preparation (the time spent at an airport after finishing the flight) are given. Our task is to decide about departures of individual flights and to find out in what order the individual flights have to be served by the individual aircraft so that the number of the aircraft used to serve the planned flights is minimal.

To model our decisions we need some variables. We will define two groups of the variables. The first group is represented by a variable $x_{i, j}$ which models our decision about transfers of aircraft among the flights $i \in I \cup\{0\}$ (please note that the symbol 0 represents a starting point which can be, for example, a hangar where the aircraft are located) and $j \in I$ (if the variable $x_{0, j}=1$, then a new aircraft is assigned to serve the flight $j \in I$ ). The second group forms the variables $y_{i}$ that model the departure times of the flights to the individual destinations.

The mathematical model has the following form [22]:

$\min f(x, y)=\sum_{j \in} x_{0, j}$

subject to:

$\sum_{i \in I \cup\{0\}} x_{i, j}=1$ for $j \in I$,

$\sum_{j \in I} x_{i, j} \leq 1$ for $i \in I$,

$y_{j}-\left(y_{i}+t_{i}+\tau_{i}\right) \geq T \cdot\left(x_{i, j}-1\right)$ for $i \in I \cup\{0\}$ and $j \in I$,

$y_{i} \leq d k$ for $i \in I$,

$x_{i, i}=0$ for $i \in I$,

$x_{i, j} \in\{0,1\}$ for $i \in I \cup\{0\}$ and $j \in I$,

and

$y_{i} \in R^{+}$for $i \in I$.

Equation (1) calculates how many aircraft we need to serve all the planned flights. The group of constraints (2) ensures that each flight is served. The group of constraints (3) assures that only one activity is planned for each aircraft after serving the flight. That means the aircraft can be assigned to a consequent flight (which must meet a time limit for the aircraft transfer) or is idle. The groups of constraints (4) and (6) model the time limits for admissible aircraft transfers among the flights. The group of constraints (5) ensures that each flight is realized in a given time interval. The groups of constraints (7) and (8) represent domains of definition for the variables used in the mathematical model. The number of the variables is equal to $m^{2}+2 m$, where $m$ defines the number of the planned flights. The number of the constraints equals to $2 m^{2}+6 m+1$.

\section{Experiments}

All the experiments were carried out using an example. The aim of the experiments was to verify functionality of the model and to find out dependence between changes of input data values (for some categories of input data) and calculation times. More specifically, we tried to change the time intervals which are intended for serving the planned flights. The calculation was done for the number of the planned flights which was equal to 5 , $10,12,14,16,18,19,20,22,24,26,28,30,32,34,36,38,40$ and 42 flights. The time interval $d k$ that is necessary to realize the planned flights was gradually modified from 160 minutes to 1000 minutes with a step equal to 30 minutes. The result of each experiment is the minimal number of the aircrafts we need to serve all the planned flights within the given time interval. The constant $t$, which expresses the time we need to fly to a certain destination, was supposed to be 100 minutes due to non-existence of real data. The constant $\tau$, which models the time the aircraft must spend at the airport after serving the flight $i \in I$, was set to 60 minutes for the same reason. The prohibitive constant $T$ was equal to $10^{6}$ for all the experiments.

The optimization experiments were carried out using software Xpress-IVE [23]. Each calculation was repeated three times. The total number of the experiments was 681 . The calculations were realized using two independent personal computers. The small-scale experiments were solved using the personal computer equipped with Intel Pentium CPU b950, 2.1 GHz and 4GB of RAM, only a demo version of software Xpress-IVE was installed on the computer. The large-scale experiments were run on the personal computer with Intel Core $26700,2.66 \mathrm{GHz}$ and $2.93 \mathrm{~GB}$ of RAM with a full version of optimization software Xpress-IVE.

The results of the experiments are summarized in Table 1. All the values of the computation times are given in seconds. The first row of each table corresponds to the number of the connections.

The second row, which is labelled $d k$, defines the time intervals that are given for serving all the planned flights. In the tables that correspond to the experiments for the number of the planned flights equal to 5 up to 19 the time intervals are divided into sub-intervals. Bounds of the sub-intervals were defined according to the number of the used aircraft. For example, in the case of 5 connections the same number of the aircraft ( 5 aircraft) 
was used when $k \in\langle 160 ; 310\rangle$. Dividing into the sub-intervals was done because of large amount of obtained data.

For the given number of the flights planned in the certain time interval, the experiment was always repeated three times. The results of the individual computational experiments (the individual calculation times) are listed in the rows labelled 1., 2. and 3. In the tables that correspond to the number of the planned flights from 5 to 19 , the range (the highest value minus the lowest value) of the calculation times we got by the experiments is given. In the tables that represent the results for the number of the planned flights greater or equal to 20 the individual calculation times are shown.

Next rows represent sample averages and variances computed on the basis of the calculation times. The row named gap represents a measure of solution inaccuracy. The gap value can be calculated using formula (9). The gap is calculated as the difference between Best solution $S_{b}$ and Best bound $B_{b}$ divided by Best solution $S_{b}$; the result is multiplied by 100 to express the gap value as a percentage. In the tables for the number of the flights lower than 20 the range for the gap values is listed. In the tables for the number of the flights greater or equal to 20 the individual gap values are shown.

gap $=\frac{S_{b}-B_{b}}{S_{b}} \cdot 100$

The last row of each table indicates the objective value that represents how many aircraft we need to serve all the planned flights. It is more than obvious that in the case of the experiments with shorter time intervals the planned flights cannot be served only by a sole aircraft. Therefore several aircrafts must be used to serve the flights.

Results of experiments

Table 1

\begin{tabular}{|c|c|c|c|c|c|}
\hline \multicolumn{6}{|c|}{ number of flights: 5} \\
\hline $\mathrm{dk}$ (intervals) [min] & $160-310$ & $340-460$ & $490-610$ & $640-790$ & $820-1000$ \\
\hline 1. $[\mathrm{s}]$ & 0 & 0 & 0 & 0 & 0 \\
\hline 2. [s] & 0 & 0 & 0 & 0 & 0 \\
\hline 3. $[\mathrm{s}]$ & 0 & 0 & 0 & 0 & 0 \\
\hline average [s] & 0 & 0 & 0 & 0 & 0 \\
\hline gap [\%] & 0 & 0 & 0 & 0 & 0 \\
\hline objective value & 5 & 3 & 2 & 2 & 1 \\
\hline \multicolumn{6}{|c|}{ number of flights: 10} \\
\hline $\mathrm{dk}$ (intervals) [min] & $160-310$ & $340-460$ & $490-610$ & $640-790$ & $820-1000$ \\
\hline 1. $[\mathrm{s}]$ & 0 & 0.1 & $0.4-17$ & $0.8-8.5$ & $6.3-84.5$ \\
\hline 2. [s] & 0 & 0.1 & $0.4-16.2$ & $0.8-8.9$ & $7.9-83$ \\
\hline 3. $[\mathrm{s}]$ & 0 & 0.1 & $0.4-16.4$ & $0.7-9.5$ & $6.3-92.6$ \\
\hline average $[\mathrm{s}]$ (variance) $\left[\mathrm{s}^{2}\right]$ & $0(0)$ & $0.1(0)$ & $5.07(39.01)$ & $6.81(8.17)$ & $40.6(942.64)$ \\
\hline gap [\%] & 0 & 0 & 0 & 0 & 0 \\
\hline objective value & 10 & 5 & 4 & 3 & 2 \\
\hline \multicolumn{6}{|c|}{ number of flights: 14} \\
\hline $\mathrm{dk}$ (intervals) [min] & $160-310$ & $340-460$ & $490-610$ & $640-790$ & 820 \\
\hline 1. $[\mathrm{s}]$ & 0 & $0.1-0.4$ & $312.1-1200$ & $3.9-1200$ & 1200 \\
\hline 2. [s] & 0 & $0.1-0.4$ & $266.5-1200$ & $3.7-1200$ & 1200 \\
\hline 3. $[\mathrm{s}]$ & 0 & $0.1-0.4$ & $268.8-1200$ & $3.8-1200$ & 1200 \\
\hline average $[\mathrm{s}]$ (variance) $\left[\mathrm{s}^{2}\right]$ & $0(0)$ & $0.19(0.002)$ & $1012.4(43244.2)$ & $806.3(35428.2)$ & $1200(0)$ \\
\hline gap [\%] & 0 & 0 & $0-80$ & $0-100$ & 100 \\
\hline objective value & 14 & 7 & 5 & 4 & 3 \\
\hline
\end{tabular}




\section{COMMNICOIIONS}

Results of experiments

Table 1

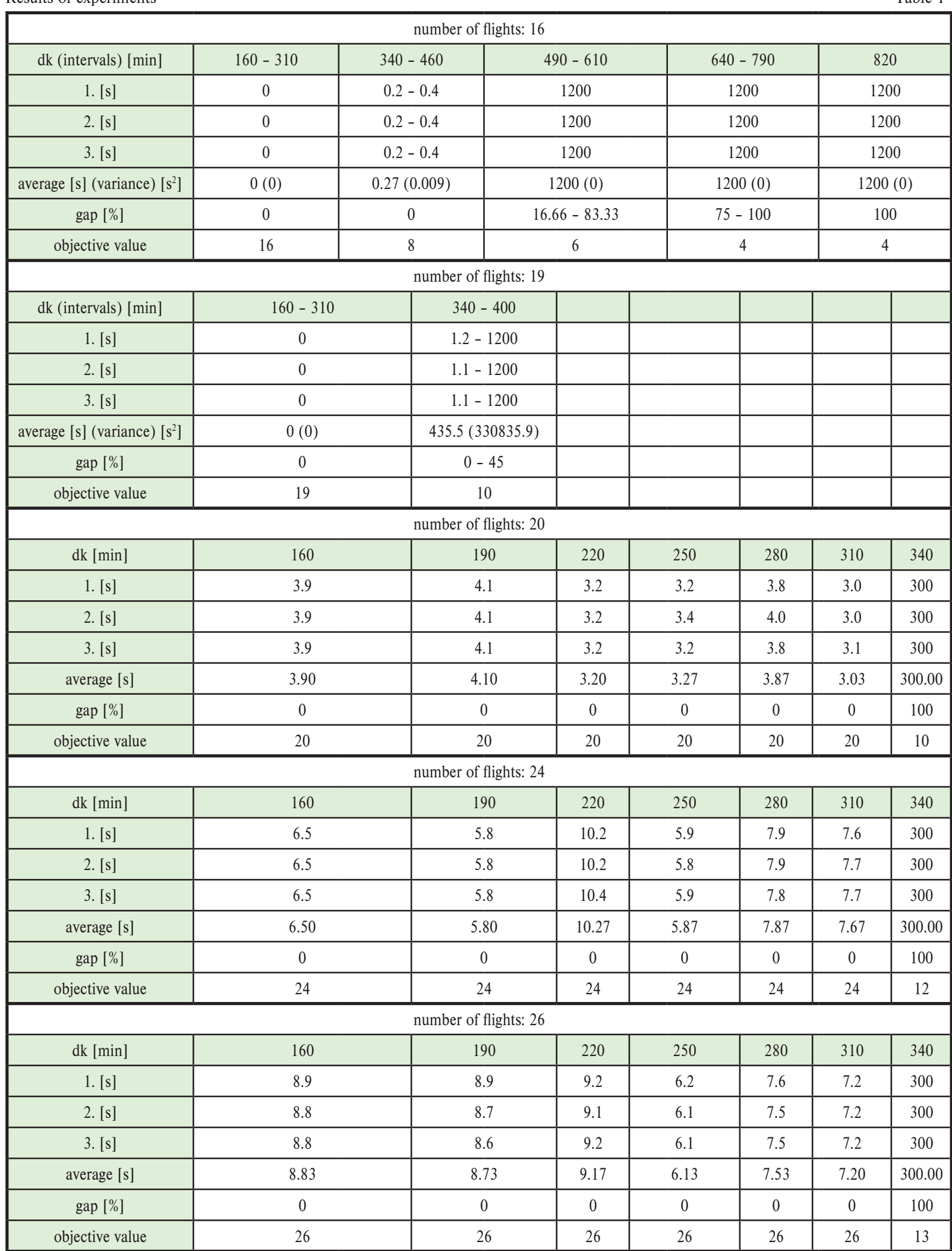




\begin{tabular}{|c|c|c|c|c|c|c|c|}
\hline \multicolumn{8}{|c|}{ number of flights: 30} \\
\hline $\mathrm{dk}[\mathrm{min}]$ & 160 & 190 & 220 & 250 & 280 & 310 & 340 \\
\hline 1. $[\mathrm{s}]$ & 10.6 & 7.4 & 8.7 & 11.0 & 7.0 & 13.2 & 300 \\
\hline 2. [s] & 10.6 & 7.4 & 8.8 & 11.0 & 7.0 & 13.2 & 300 \\
\hline 3. $[\mathrm{s}]$ & 10.6 & 7.4 & 8.7 & 11.0 & 7.0 & 13.2 & 300 \\
\hline average [s] & 10.60 & 7.40 & 8.73 & 11.00 & 7.00 & 13.20 & 300.00 \\
\hline gap [\%] & 0 & 0 & 0 & 0 & 0 & 0 & 100 \\
\hline objective value & 30 & 30 & 30 & 30 & 30 & 30 & 15 \\
\hline \multicolumn{8}{|c|}{ number of flights: 34} \\
\hline $\mathrm{dk}[\mathrm{min}]$ & 160 & 190 & 220 & 250 & 280 & 310 & 340 \\
\hline 1. $[\mathrm{s}]$ & 22.1 & 17.8 & 13.9 & 14.2 & 15.8 & 14.2 & 300 \\
\hline 2. [s] & 22.0 & 18.0 & 13.9 & 14.2 & 15.7 & 14.2 & 300 \\
\hline 3. $[\mathrm{s}]$ & 22.0 & 17.8 & 14.1 & 14.3 & 15.7 & 14.1 & 300 \\
\hline average [s] & 22.03 & 17.87 & 13.97 & 14.23 & 15.73 & 14.17 & 300.00 \\
\hline gap [\%] & 0 & 0 & 0 & 0 & 0 & 0 & 100 \\
\hline objective value & 34 & 34 & 34 & 34 & 34 & 34 & 17 \\
\hline \multicolumn{8}{|c|}{ number of flights: 38} \\
\hline $\mathrm{dk}[\mathrm{min}]$ & 160 & 190 & 220 & 250 & 280 & 310 & 340 \\
\hline 1. $[\mathrm{s}]$ & 38.0 & 32.4 & 24.8 & 25.6 & 31.3 & 38.7 & 300 \\
\hline 2. [s] & 38.1 & 33.4 & 24.7 & 25.7 & 31.2 & 38.8 & 300 \\
\hline 3. $[\mathrm{s}]$ & 37.9 & 33.3 & 24.7 & 25.6 & 31.2 & 38.8 & 300 \\
\hline average [s] & 38.00 & 33.03 & 24.73 & 25.63 & 31.23 & 38.77 & 300.00 \\
\hline gap [\%] & 0 & 0 & 0 & 0 & 0 & 0 & 100 \\
\hline objective value & 38 & 38 & 38 & 38 & 38 & 38 & 19 \\
\hline \multicolumn{8}{|c|}{ number of flights: 40} \\
\hline $\mathrm{dk}[\mathrm{min}]$ & 160 & 190 & 220 & 250 & 280 & 310 & 340 \\
\hline 1. $[\mathrm{s}]$ & 51.5 & 65.9 & 36.0 & 37.0 & 36.4 & 38.5 & 300 \\
\hline 2. [s] & 51.3 & 66.4 & 36.2 & 37.0 & 36.5 & 38.5 & 300 \\
\hline 3. [s] & 51.4 & 66.5 & 36.2 & 37.1 & 36.5 & 38.5 & 300 \\
\hline average [s] & 51.40 & 66.27 & 36.13 & 37.03 & 36.47 & 38.50 & 300.00 \\
\hline gap [\%] & 0 & 0 & 0 & 0 & 0 & 0 & 100 \\
\hline objective value & 40 & 40 & 40 & 40 & 40 & 40 & 20 \\
\hline
\end{tabular}

\section{Conclusions}

During the testing the model solvability we carried out 681 calculations. By the testing we evaluate the functionality of the linear mathematical model. According to our assumptions the number of the aircraft we need to serve all the planned flights decreases with the increasing length of the time interval we have for realization of the flights. By the testing we proved the dependence of computation times on the number of the flights - see Fig. 1.
On the basis of obtained data the general dependence of the calculation time on the interval width and on the number of the planned flights was confirmed. The experiments revealed that if the interval width and the number of the planned flights increase, the calculation time increases as well. The experiments also showed that the proposed mathematical model is relatively efficient for lower numbers of the planned flights per day (approximately up to 15 connections per day, such number is enough for middle charter airlines) and enables its practical using. 


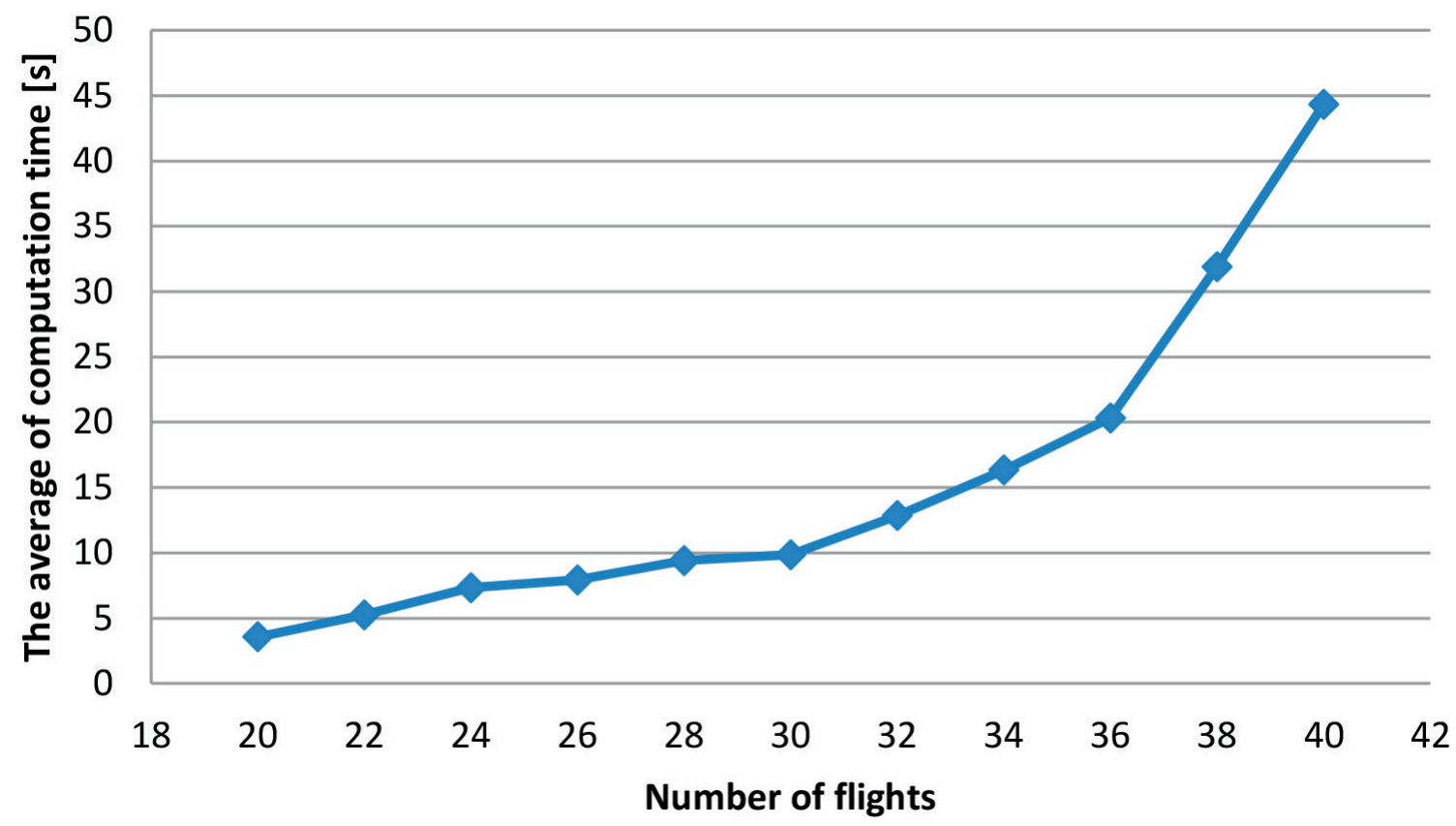

Fig. 1 The dependence of computation times on the number of the flights

\section{References}

[1] BINA, L., BINOVA, H.; PLOCH, J., ZIHLA, Z.: Operation of Aviation Technology and Logistics (in Czech), Brno : CERN, 2014, ISBN 978-80-7402-855-7.

[2] GRAF, V.: Timetable Optimization for Charter Air Transport Company, Ostrava: VSB-TU Ostrava, 2014, $71 \mathrm{p}$.

[3] KePAPTSOGLOU, K.; KARLAFTIS, M.: Transit Route Network Design Problem: Review, J. of Transportation Engineering, 2009, vol. 135, No. 8, pp. 491-505.

[4] SCHOBEL, A.: Line Planning in Public Transportation: Models and Methods, OR Spectrum, 2012, vol. 34, No. 3, pp. $491-510$.

[5] CERNY, J., CERNA, A.: Erlander Principle in Managerial Decision Making on Czech and Slovak Urban Transport Routes, Economics and Management, 2013, vol. 16, No. 1, pp. 93-100.

[6] CERNA, A., CERNY, J., PRIBYL, V.: Economically Optimal Road Subnetwork, Communication - Scientific Letters of the University of Zilina, vol. 16, No. 2, 2014, pp. 83-91.

[7] BABEL, L.; KELLERER, H.: Design of Tariff Zones in Public Transportation Networks: Theoretical Results and Heuristics, Mathematical Methods of Operations Research, 2003, pp. 359-374.

[8] HARNACHER, H., W., SCHOBEL, A.: Design of Zone Tariff Systems in Public Transportation, Operational Research, 2004 , vol. 52, No. 6, pp. 897-908.

[9] KOHANI, M.: Designing of Zone Tariff in Integrated Transports, Communication - Scientific Letters of the University of Zilina, 2013, vol. 15, No. 1, pp. 29-33.

[10] PALUCH, S.: On a Fair Fare Rating on a Bus line, Communication - Scientific Letters of the University of Zilina, 2013, vol. 15, No. 1, pp.25-38.

[11] GABRISOVA, L.; KOZEL, P.: Coordination of Bus Departures by Mathematical Programming, Communication - Scientific Letters of the University of Zilina, 2013, vol. 15, No. 1, pp.74-79.

[12] PALUCH, S.: Trip Coordination in Municipal Passenger Transport, Transport Problems, 2014, vol. 9, No. 2, pp.111-117. 
[13] PALUCH, S.: Bus Scheduling as a Graph Coloring Problem, Communication - Scientific Letters of the University of Zilina, 2003, vol. 5, No. 4, pp.16-20.

[14] CERNY, J., KLUVANEK, P.: An Introduction to Mathematical Theory of Transport, Bratislava: ALFA, 1990, ISBN 80-224-0099-8.

[15] CERNY, J.: Optimization models and methods for scheduling in regional transport. Proc. of intern. conference Veda o doprave, November 2001, Praha : Fakulta dopravni, CVUT Praha, pp. 54-59. ISBN 80-01-02437-7.

[16] CERNA, A., CERNY, J.: Control and Decision Theory in Transport Systems, Pardubice: Institut Jana Pernera, 2004,150 p., ISBN 80-86530-15-9.

[17] MERCIER, A., SOUMIS, F. An Integrated Aircraft Routing, Crew Scheduling and Flight Retiming Model. Computers \& Operations Research, vol. 34, 2007, pp. 2251-2265.

[18] SRIRAM, CH., HAGHANI, A.: An Optimization Model for Aircraft Maintenance Scheduling and Re-assignment. Transportation Research - Part A, vol. 37, 2003, pp. 29-48.

[19] LEE, L.H., LEE, CH. U., TAN, Y.P.: A Multi-objective Genetic Algorithm for Robust Flight Scheduling UsingS. European J. of Operational Research, vol. 177, 2007, pp. 1948-1968.

[20] MERCIER, A., CORDEAU, J-F., SOUMIS, F.: A Computational Study of Benders Decomposition for the Integrated Aircraft Routing and Crew Scheduling Problem. Computers \& Operations Research, vol. 32, 2005, pp.1451-1476.

[21] EL MOUDANI, W., MORA-CAMINO, F.: A Dynamic Approach for Aircraft Assignment and Maintenance Scheduling by Airlines. J. of Air Transport Managament, vol. 6, 2000, pp. 233-237.

[22] BURKE, E. K., DE CAUSMAECKER, P., DE MAERE, G., MULDER, J., PAELINCK, M., VANDEN BERGHE, G.: A Multiobjective Approach for Robust Airline Scheduling. Computers \& Operations Research, vol . 37, 2010, pp. 822-832.

[23] FAIR ISAAC CORPORATIN. [online]. @2014 [20-2-2014]. http://www.fico.com/en/products/fico-xpress-optimization-suite/. 